\title{
Duration of Preoperative External Ventricular Drain in Pediatric Posterior Fossa Tumors-Does It Matter?
}

\author{
Ehtesham Ghani, Ayman AlBanyan, Abdulrahman Sabbagh, Maqsood Ahmad \\ Department of Pediatric Neurosurgery, National Neuroscience Institute, King Fahad Medical City, Riyadh, KSA \\ Email: ehteshamghani123@yahoo.com,ighani@kfmc.med.sa
}

How to cite this paper: Ghani, E., AlBanyan, A., Sabbagh, A. and Ahmad, M. (2017) Duration of Preoperative External Ventricular Drain in Pediatric Posterior Fossa Tumors-Does It Matter? Open Journal of Pediatrics, 7, 86-97.

https://doi.org/10.4236/ojped.2017.72012

Received: February 20, 2017

Accepted: June 17, 2017

Published: June 20, 2017

Copyright $\odot 2017$ by authors and Scientific Research Publishing Inc. This work is licensed under the Creative Commons Attribution International License (CC BY 4.0).

http://creativecommons.org/licenses/by/4.0/

\begin{abstract}
Objective: Aim of the study was to assess the duration of preoperative external ventricular drain (EVD) as a predictor for permanent cerebrospinal fluid (CSF) diversion in pediatric posterior fossa tumors. Methods: The study was conducted in the Department of Pediatric Neurosurgery, National Neuroscience Institute, King Fahad Medical City, Riyadh, Saudi Arabia from January 2010 to December 2013. The data were collected retrospectively. The patients who had emergency insertion of external ventricular drain (EVD) due to hydrocephalus before the definitive posterior fossa tumor surgery were included in the study. Results: The preoperative emergency insertion of EVD was done in 38 patients with pediatric posterior fossa tumors. The patients were divided into two groups. Group A consists of those patients who had duration of preoperative EVD equal or less than 7 days. Group B includes those patients who had duration of preoperative EVD more than 7 days. Group A has 16 patients while Group B has 22 patients. The predominant clinical feature was symptoms and signs of raised intracranial pressure (ICP) only. Infection related to EVD was seen in seven patients. Ventriculoperitoneal (VP) shunt was required in $31.25 \%$ of Group A patients and $18.18 \%$ of Group B patients (p value $=0.35)$. Overall shunt rate was $23.68 \%$. Conclusion: There are well known number of factors that can determine the need of permanent CSF diversion in patients with posterior fossa tumors. However, there is no effect of preoperative duration of EVD in determining the requirement of postoperative VP shunt.
\end{abstract}

\section{Keywords}

Posterior Fossa Tumors, External Ventricular Drain, Hydrocephalus, Ventriculoperitoneal Shunt, CSF Diversion 


\section{Introduction}

The development of posterior fossa tumor surgery remains Harvey Cushing's hallmark contribution to pediatric neurosurgery [1]. He was first to publish a large series of 61 patients with cerebellar medulloblastomas [2]. Before the era of Cushing, posterior fossa tumors were considered as inoperable and only bony decompression used to be offered. Since then, the evolution of surgical technique reflects the maturation of modern neurosurgery. Majority of patients with posterior fossa tumors have hydrocephalus at the time of presentation [3]. The management of hydrocephalus with posterior fossa tumors remains controversial. In recent studies, permanent postoperative cerebrospinal fluid (CSF) diversion was required in $30 \%-38.7 \%$ of the patients [4] [5] [6]. However, awareness regarding factors that predict the need for CSF diversion following posterior fossa tumor surgery are essential for the surgeons during counseling, surgical planning, postoperative course and radiological monitoring [7]. Such factors include age of the patient, duration of history, location of the tumor, type of the tumor (solid or cystic), severity of hydrocephalus, tumor resection, CSF infection, CSF leak and pseudomeningocele [3] [7] [8] [9].

The different surgical options are used to treat hydrocephalus. Previously some surgeons used to do separate burr hole routinely at the time of posterior fossa tumor surgery. Currently surgeons prefer CSF diversion through shunts, external ventricular drainage (EVD) or endoscopic third ventriculostomy (ETV). Each of these has its own merits and demerits. Reliability of EVD as a predictor of permanent CSF diversion is debatable. Most of the authors believe that longer the postoperative duration of EVD means permanent CSF diversion [8] [10]. However, we did not find any study in the literature mentioning the preoperative duration of EVD effects shunt dependency. Therefore, we conducted this study to assess the duration of preoperative EVD in posterior fossa tumor surgery as a predictor for permanent CSF diversion.

\section{Methods}

The study was conducted in the Department of Pediatric Neurosurgery, National Neuroscience Institute, King Fahad Medical City, Riyadh, Saudi Arabia from January 2010 to December 2013. The patients were enrolled retrospectively. The data were collected and were registered on the proforma. All the data were reviewed. Data were generated from the clinical, operative and radiological records. Categorical data were summarized as number and percentage. Continuous data was summarized as mean and standard deviation. Comparison between the groups for categorical variable was done using chi-square test or Fisher's exact test and for continuous data student-t test or Mann Whitney u was used. Any association with p-value of less than 0.05 was considered as statistically significant. All statistical analysis was performed using SAS version 9.2 (SAS Institute, Inc, Cary, NC).

The patients who had insertion of EVD before the definitive posterior fossa tumor surgery in pediatric age were included. All such patients presented in 
emergency due to severe hydrocephalus. These patients underwent emergency insertion of EVD after CT scan. Later, magnetic resonance imaging (MRI) of brain and spine were done before undergoing definitive posterior fossa tumor surgery in all patients. Most of the patients required MRI under general anesthesia. After tumor surgery, the patients were considered for challenging of EVD around on $7^{\text {th }}$ postoperative day. If there were no clinical and radiological signs of hydrocephalus, EVD was removed. Otherwise, insertion of ventriculoperitoneal (VP) shunt was done.

The patients who were managed without EVD or with intraoperative insertion of EVD, who had shunt insertion before posterior fossa tumor surgery and who had surgery for recurrence were excluded from the study.

The time interval between insertion of EVD and definite tumor surgery was considered in dividing the patients in two groups. Group A consists of those patients who had duration of preoperative EVD equal or less than 7 days. Group B includes those patients who had duration of preoperative EVD more than 7 days. Different factors were studied in each group including age and sex of the patient, duration of symptoms, clinical presentation, duration of MRI after admission, location of the tumor, CSF seeding, amount of surgical resection, type of the tumor on histopathology, duration of postoperative EVD, CSF leak, pseudomeningocele, EVD related infection and VP shunt insertion. Data were analyzed and the literature was reviewed.

\section{Results}

The preoperative emergency insertion of EVD was done in 38 pediatric patients with posterior fossa tumor (Figure 1). Mean duration of preoperative EVD was 5.44 days in Group A and 13.72 days in Group B. Group A has 16 patients while Group B has 22 patients. In Group B, initially parents of three patients refused surgery and later they agreed. Mean age was 4.5 year in Group A and 5.5 year in Group B. Male to female ratio was 1:0.6 in Group A and 1:0.8 in Group B. The predominant clinical feature was symptoms an $d$ signs of raised intracranial pressure (ICP) only (Figure 2). Those were seen exclusively in $81.25 \%$ of patients in Group A and 77.27\% of patients in Group B. The most of the patients presented with short duration of symptoms in both groups and had midline tumor (Figure 3). CSF seedings were appreciated in five patients in Group A and four patients in Group B ( $p$ value $=0.81$ ). Gross total resection was achieved in $81.25 \%$ and $81.82 \%$ in Group A and B respectively. Medulloblastoma was the prime histopathologic diagnosis in both groups. It was followed by pilocytic astrocytoma, anaplastic ependymoma, cavernous hemangioma and Ewing's sarcoma. CSF leak was observed in total of five patients (13.16\%). It was seen in three patients in Group A and two patients in Group B ( $p$ value $=0.63$ ). Pseudomeningocele was noted in six patients overall. It was found in two patients in Group A and four patients in Group B ( $p$ value $=0.63$ ). Postoperatively EVD was kept in for mean of 17.44 days in Group A and 16.59 days in Group B.

Seven patients had EVD related infection (Figure 4). Preoperative EVD re- 


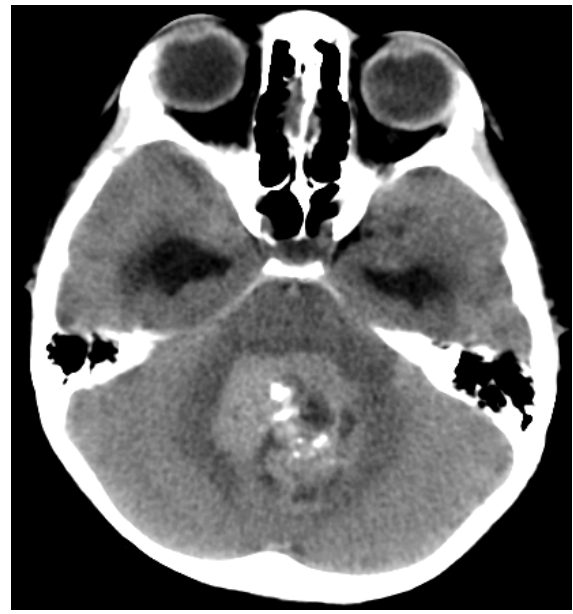

(a)

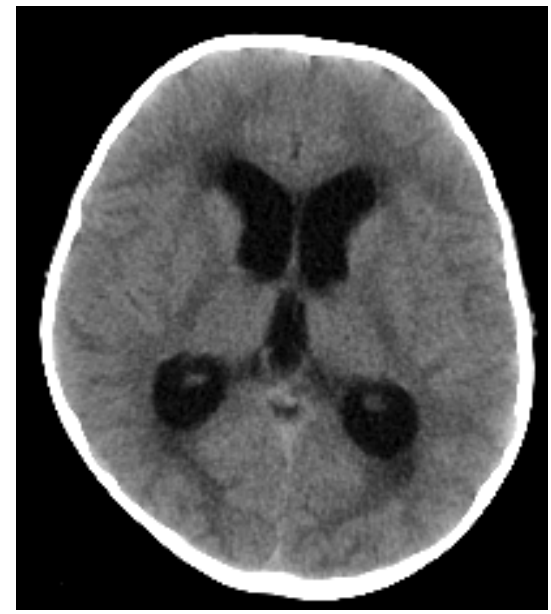

(b)

Figure 1. Plain axial CT scans of 8 year old boy with posterior fossa tumor which is partially calcified (a) and associated with acute hydrocephalus (b).

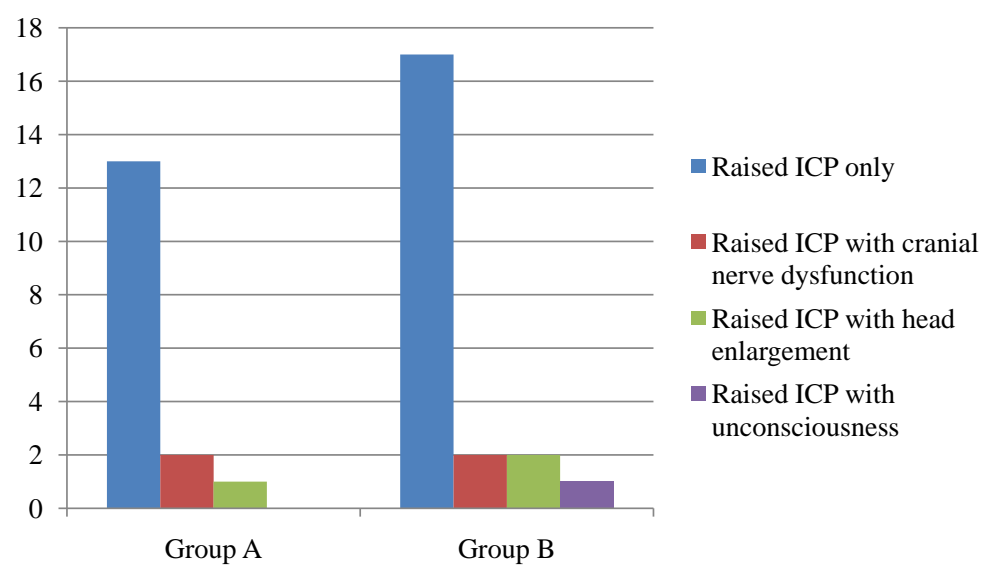

Figure 2. Clinical features.

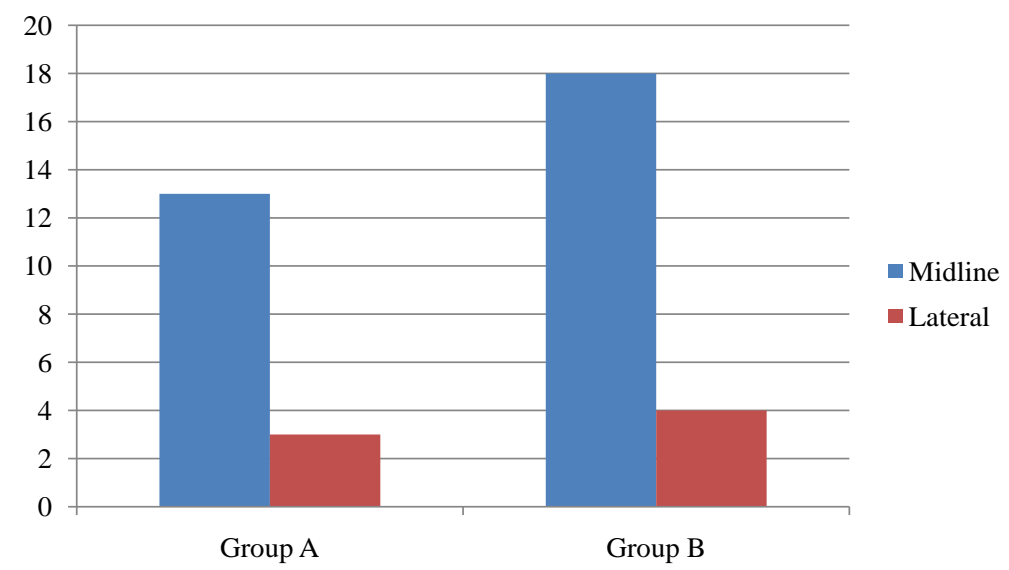

Figure 3. Location of tumours.

lated infection secondary to Klebsiella pneumoniae was seen in one patient in Group B. He did not require shunt. There were three patients in each group who had postoperative EVD related infection with $18.75 \%$ in Group A and $13.64 \%$ in 
Group B ( $\mathrm{p}$ value $=0.64)$. In Group A, infection was caused by Klebsiella pneumoniae, Acinetobacter baumannii and Pseudomonas aeruginosa. In Group B, Klebsiella pneumoniae, Staphylococcus epidermidis and Enterobacter aerogenes were cultured from CSF. Once the infection is clear, all patients in Group A with infection and in Group B with Klebsiella pneumoniae and Staphylococcus epidermidis infection required shunt surgery. Overall, infection was seen in $18.4 \%$ of the patients. However, six patients who had infection eventually required VP shunt. VP shunt (Figure 5) was required in $31.25 \%$ of Group A patients and $18.18 \%$ of Group B patients ( $\mathrm{p}$ value $=0.35$ ). In total, shunt insertion rate was $23.68 \%$. All the patients were followed up closely for six months. Results are shown in Table 1.

\section{Discussion}

The posterior fossa is a limited space in the cranium. The tumors in this region usually present earlier. Posterior fossa tumors are the most common primary neoplasms in children. Such tumors require prompt decision and quick action as the most of the patients have associated hydrocephalus at presentation [3]. Early treatment will eventually affect the morbidity and mortality. However, there is

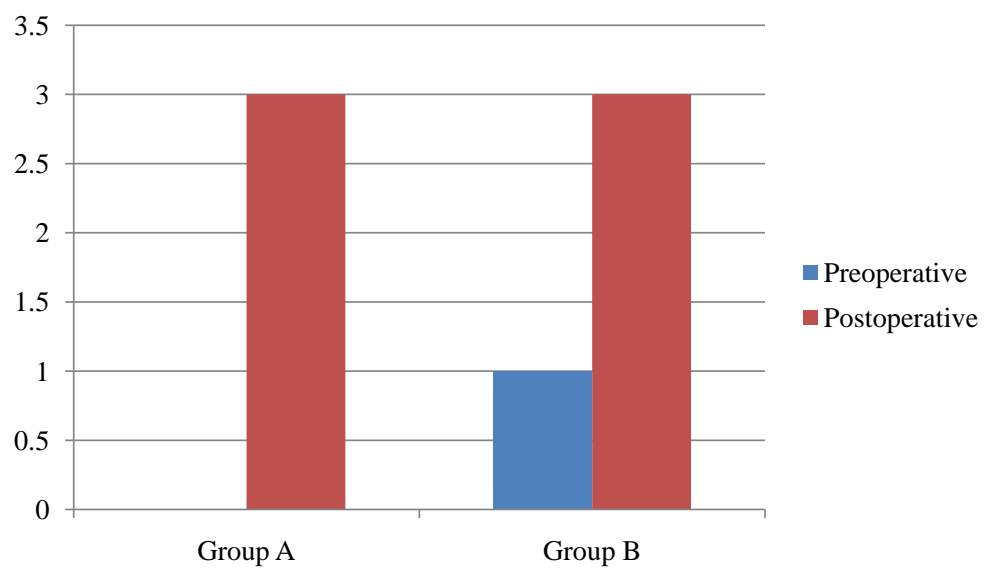

Figure 4. EVD related infection (seven patients).

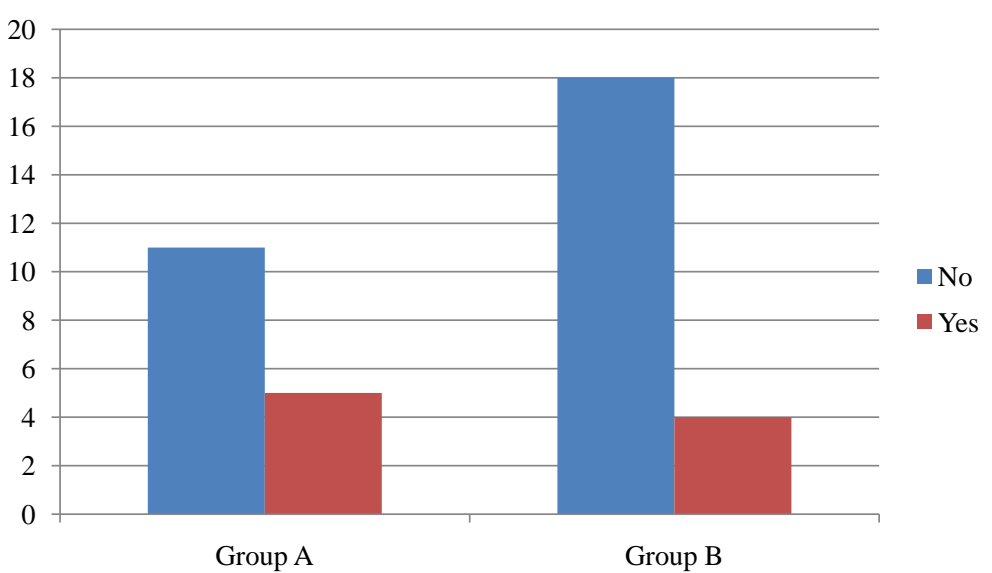

Figure 5. Postoperative VP shunt insertion. 
Table 1. Breakdown of the data.

\begin{tabular}{|c|c|c|c|c|}
\hline Factors & $\begin{array}{c}\text { Group A } \\
\text { (EVD less than } 7 \text { days) } \\
\text { Mean }=5.44 \pm 1.78 \text { days }\end{array}$ & $\begin{array}{c}\text { Group B } \\
\text { (EVD more than } 7 \text { days) } \\
\text { Mean }=13.72 \pm 5.81\end{array}$ & $\begin{array}{c}\text { Overall } \\
\text { Mean }=10.23 \pm 6.14\end{array}$ & P-value \\
\hline Number of Patients (n) & 16 & 22 & 38 & \\
\hline \multicolumn{5}{|l|}{ Age (In Months) } \\
\hline Mean \pm SD & $54.19 \pm 24.52$ & $66.73 \pm 33.57$ & $61.45 \pm 30.37$ & 0.21 \\
\hline \multicolumn{5}{|l|}{ Sex } \\
\hline Male, n (\%) & $10(62.50 \%)$ & $12(54.55 \%)$ & $22(57.89 \%)$ & 0.62 \\
\hline Female, n (\%) & $6(37.50 \%)$ & $10(45.45 \%)$ & $16(42.11 \%)$ & \\
\hline \multicolumn{5}{|l|}{ Duration of Symptoms } \\
\hline Less than 1 month, n (\%) & $10(62.50 \%)$ & $14(63.64 \%)$ & $24(63.16 \%)$ & 0.94 \\
\hline More than 1 month, n (\%) & $6(37.50 \%)$ & $8(36.36 \%)$ & $14(36.84 \%)$ & \\
\hline \multicolumn{5}{|l|}{ Clinical Features } \\
\hline Signs of raised ICP only, n (\%) & $13(81.25 \%)$ & $17(77.27 \%)$ & $30(78.95 \%)$ & 0.81 \\
\hline $\begin{array}{l}\text { Signs of raised ICP with } \\
\text { cranial nerve deficits, } n(\%)\end{array}$ & $2(12.50 \%)$ & $2(9.09 \%)$ & $4(10.53 \%)$ & \\
\hline $\begin{array}{l}\text { Signs of raised ICP with head enlargement } \\
\text { or delayed milestones, } \mathrm{n}(\%)\end{array}$ & $1(6.25 \%)$ & $2(9.09 \%)$ & $3(7.89 \%)$ & \\
\hline $\begin{array}{l}\text { Signs of raised ICP with loss } \\
\text { of consciousness, } \mathrm{n}(\%)\end{array}$ & $0(0.00 \%)$ & $1(4.55 \%)$ & $1(2.63 \%)$ & \\
\hline \multicolumn{5}{|l|}{ Duration of MRI (In Days) } \\
\hline Mean \pm SD & $3.25 \pm 1.69$ & $4.41 \pm 1.79$ & $3.92 \pm 1.82$ & 0.04 \\
\hline \multicolumn{5}{|l|}{ Location of the Tumour } \\
\hline Midline, n (\%) & $13(81.25 \%)$ & $18(81.82 \%)$ & $31(81.58 \%)$ & 0.96 \\
\hline Lateral, n (\%) & $3(18.75 \%)$ & $4(18.18 \%)$ & $7(18.42 \%)$ & \\
\hline \multicolumn{5}{|l|}{ CSF Seeding } \\
\hline No, n (\%) & $11(68.75 \%)$ & $18(81.82 \%)$ & $29(76.32 \%)$ & 0.80 \\
\hline Yes, n (\%) & $5(31.25 \%)$ & $4(18.18 \%)$ & $9(23.68 \%)$ & \\
\hline \multicolumn{5}{|l|}{ Diagnosis } \\
\hline Medulloblastoma, n (\%) & $8(50.00 \%)$ & $14(63.64 \%)$ & $22(57.89 \%)$ & 0.65 \\
\hline Pilocytic astrocytoma, n (\%) & $3(18.75 \%)$ & $5(22.73 \%)$ & $8(21.05 \%)$ & \\
\hline Anaplastic ependymoma, $\mathrm{n}(\%)$ & $3(18.75 \%)$ & $2(9.09 \%)$ & $5(13.16 \%)$ & \\
\hline Ewing's sarcoma, n (\%) & $1(6.25 \%)$ & $0(0.00 \%)$ & $1(2.63 \%)$ & \\
\hline Cavernous haemangioma, $\mathrm{n}(\%)$ & $1(6.25 \%)$ & $1(4.55 \%)$ & $2(5.26 \%)$ & \\
\hline \multicolumn{5}{|l|}{ Surgery } \\
\hline Gross total, n (\%) & $13(81.25 \%)$ & $18(81.82 \%)$ & $31(81.58 \%)$ & 0.96 \\
\hline Subtotal, n (\%) & $3(18.75 \%)$ & $4(18.18 \%)$ & $7(18.42 \%)$ & \\
\hline \multicolumn{5}{|l|}{ CSF Leak } \\
\hline No, n (\%) & $13(81.25 \%)$ & $20(90.91 \%)$ & $33(86.84 \%)$ & 0.63 \\
\hline
\end{tabular}




\section{Continued}

\begin{tabular}{|c|c|c|c|c|}
\hline Yes, n (\%) & $3(18.75 \%)$ & $2(9.09 \%)$ & $5(13.16 \%)$ & \\
\hline \multicolumn{5}{|l|}{ Pseudomeningocele } \\
\hline No, n (\%) & $14(87.50 \%)$ & $18(81.82 \%)$ & $32(84.21 \%)$ & 0.63 \\
\hline Yes, n (\%) & $2(12.50 \%)$ & $4(18.18 \%)$ & $6(15.79 \%)$ & \\
\hline \multicolumn{5}{|l|}{ Infection } \\
\hline No, n (\%) & $13(81.25 \%)$ & $18(81.82 \%)$ & $31(81.58 \%)$ & 0.64 \\
\hline Postoperative, n (\%) & $3(18.75 \%)$ & $3(13.64 \%)$ & $6(15.79 \%)$ & \\
\hline Preoperative, n (\%) & $0(0.00 \%)$ & $1(4.55 \%)$ & $1(2.63 \%)$ & \\
\hline \multicolumn{5}{|l|}{ Insertion of VP Shunt } \\
\hline No, n (\%) & $11(68.75 \%)$ & $18(81.82 \%)$ & $29(76.32 \%)$ & 0.35 \\
\hline Yes, n (\%) & $5(31.25 \%)$ & $4(18.18 \%)$ & $9(23.68 \%)$ & \\
\hline \multicolumn{5}{|c|}{ Duration of Postoperative EVD } \\
\hline Mean \pm SD & $17.44 \pm 13.87$ & $16.59 \pm 17.28$ & $16.95 \pm 15.73$ & 0.42 \\
\hline
\end{tabular}

no consensus on the management of hydrocephalus secondary to posterior fossa tumor [7]. It can be managed before, during and after posterior fossa tumor surgery [11].

In 1963, Abraham and Chandy managed the hydrocephalus related to posterior fossa tumors with ventriculoatrial (VA) shunts [12]. This method of managing the hydrocephalus became popular. Many neurosurgeons adopted the policy of putting VP or VA shunts before the definitive posterior fossa tumor surgery to have a better operative field. It resulted in $100 \%$ of the patients having permanent shunt insertion or dependency [13]. In 1985, the American Society of Pediatric Neurosurgery commissioned a study to find out the best way to manage the dilemma of hydrocephalus secondary to posterior fossa tumors. Robert McLaurin made the conclusion after obtaining the data from different hospitals of North America that there was no clear evidence of having any advantage to do preoperative shunt insertion [14]. It is still a matter of discussion.

Management of hydrocephalus secondary to posterior fossa tumors includes insertion of EVD, ETV, shunt insertion and no treatment at all [11]. Some surgeons in the past preferred to place a separate burr hole routinely during the posterior fossa tumor surgery to drain the ventricles [15]. Ventricular tap was also used in infants with open fontanel [16]. Recently Ommaya reservoir was used as an alternate to EVD, VP shunt and ETV. It is associated with lesser trauma and fewer complications [17]. Relieving the hydrocephalus in the presence of posterior fossa tumor can cause sudden decompression. It may lead to the formation of extradural hematoma [18]. ETV and VP shunt are recommended as permanent treatment for hydrocephalus after posterior fossa tumor surgery [11].

There are number of factors that can determine the need for CSF diversion after the surgery. All these factors are debatable. Most of the surgeons believe 
that age at surgery is related to postoperative CSF diversion. Younger the patient means more chance of having permanent CSF diversion after surgery [9]. However; some surgeons observed that mean age at diagnosis and extent of tumor resection do not affect the need for CSF diversion. It was also noted that the patients who presented with duration of symptoms less than 3 months had higher rate of postoperative CSF diversion [7]. It is believed that midline tumors require more shunts than laterally located tumors [7] [9]. Medulloblastoma and ependymoma are more associated with postoperative CSF diversion [3]. Patients with meningitis and pseudomeningocele have higher risk of shunt requirement [7].

VP shunt is still an option to treat hydrocephalus preoperatively. It can be done in those patients who are in poor neurological state as a result of delayed diagnosis and advanced disease. Papilledema responds well to VP shunt. It significantly reduces the overall morbidity and mortality. It may result in shunt infection and malfunction [8] [19]. However, it can cause upward herniation, tumor hemorrhage and peritoneal seeding. It will be difficult to make a plane between the tumor and adjacent normal brain and brain stem during tumor surgery [19] [20]. Preoperative VP shunt requirement varied from $29 \%-43.1 \%$ after using different surgical options for the treatment of hydrocephalus depending on the presentation [19] [21]. It also depends on the policy of the center.

The use of preoperative ETV is an effective, feasible and safe procedure [22]. It is helpful in immediate and long term control of hydrocephalus [10]. It eliminates the risk of CSF infection related to EVD and avoids the complications of VP shunt like infection and malfunction. In developing countries where the presentation is late, ETV is recommendable option due to large ventricles [22]. However, ETV cannot always prevent postoperative hydrocephalus in all cases of posterior fossa tumors. The use of postoperative VP shunt is the alternative [10]. VP shunt was required in 6\% of the patients after ETV for hydrocephalus related to posterior fossa tumor [20].

EVD placement is one of the most commonly performed neurosurgical procedures. It is an effective alternate method to insertion of preoperative shunts [23]. It can be inserted preoperatively or intraoperatively. Preoperative EVD insertion is indicated in those patients who present in emergency with symptoms and signs of raised ICP. Care should be taken not to drain CSF quickly. ICP is usually high and is more than $30 \mathrm{~cm}$ of water in most of the cases [24]. The goal is to do slow controlled sustained decompression of ICP. It is one of the advantages as compared to the shunt where pressure of the valve is predetermined. One can adjust the level of EVD depending on the ICP. It is a live saving emergency procedure. It controls ICP before, during and after surgery [25]. It allows the drainage of blood and debris from CSF after tumor surgery [19]. Moreover, it provides smooth postoperative course. It decreases the possibility of aseptic meningitis and postoperative shunts [23]. It also prevents CSF leak and helps in wound healing by keeping the surgical wound dry [19]. However, it may result in tumoral hemorrhage and upward herniation [10]. The main issue related to 
EVD is CSF infection. It can be left safely, as long as needed, provided that meticulous care is taken for EVD insertion and nursing. EVD duration seems to have no effect on incidence of infection [26]. Infection rate of $7 \%-10 \%$ was noted per procedure [27]. More than five days of drainage seems to raise concern for infection risk, though the weight of evidence shows long term drainage is safe and the routine catheter changes have led to higher not lower infection rates [28] [29]. Tunneling the catheter from insertion site as far as possible is preferred. Prophylactic systemic antibiotic use for the duration of drainage has shown little benefit. Antibiotic-impregnated EVD reduces the chance of catheter related infections [30]. Overall, meticulous technique at the time of insertion, cautious wound care, and aseptic technique during CSF sampling are essential to reduce infection rates. In our study, EVD related CSF infection was seen postoperatively in three patients in both groups. Only one patient had infection preoperatively in group B. None of the patient had infection preoperatively in group A. Overall infection rate was $18.4 \%$. Gopalakrishnan et al. stated that children who underwent intraoperative EVD insertion had shunt rate of $39.6 \%$ compared with $16.7 \%$ of those who did not have an EVD [7]. The postoperative VP shunt was required in 6.1-19\% the patients who had intraoperative EVD [19] [23] [25]. Some advocate that there is no association of EVD with the need of postoperative CSF diversion [21] [24]. While others had concluded that EVD dependence is a reliable predictor for permanent CSF diversion [31] [32]. In one study, $95.2 \%$ of the patients had symptomatic hydrocephalus but postoperative VP shunt was required in $29.8 \%$ of the patients. These were managed with either intraoperative EVD or without CSF diversion [7]. Most of the surgeons believe that eventually one third of the patients will require postoperative CSF diversion. Rate of VP shunt insertion was 30\% - 38.7\% in different studies [5] [6] [9] [19]. Schmid inserted EVD 2 - 5 days before definitive posterior fossa tumor surgery. His shunt free rate in children was $83 \%$ and infection rate was $4.9 \%$. A shunt was inserted only if the CSF pathways remained obstructed after tumor removal [24]. With this regimen, shunt insertion rate can be lowered down with the risk of infection. We did not find any study in the literature that suggests that duration of preoperative EVD has any effect on postoperative permanent CSF diversion. In our study, not only our patients were symptomatic as they presented with signs and symptoms of raised ICP and they all were in need for emergency EVD insertion to relieve the pressure. Eventually, VP shunt was required in nine patients with $31.25 \%$ of the patients in group A and $18.18 \%$ of the patients in group B. These numbers may suggest that the longer duration of preoperative EVD can reduce the need for permanent CSF diversion postoperatively. But statistically these numbers have no significance $(\mathrm{p}$ value $=0.35$ ). Overall, our shunt free rate was $76.3 \%$.

\section{Conclusion}

Still there is no agreement on the management of hydrocephalus due to posterior fossa tumors. It depends on surgeon's preferences, case to case variations 
and departmental policies and guidelines. All patients had severe hydrocephalus at presentation in our study. While using single modality for the management of hydrocephalus, permanent shunt insertion rate was comparably low. However, there is no effect of preoperative duration of EVD in determining the requirement of postoperative VP shunt.

\section{Acknowledgements}

We are grateful to Mr. Anhar Ullah from department of cardiac sciences, College of Medicine, King Saud University, Riyadh, Saudi Arabia, for his support and work in analyzing the data.

\section{References}

[1] Cohen-Gadol, A.A. and Spencer, D.D. (2004) Inauguration of Pediatric Neurosurgery by Harvey W. Cushing: His Contributions to the Surgery of Posterior Fossa Tumors in Children. Historical Vignette. Journal of Neurosurgery, 100, 225-231.

[2] Cushing, H. (1930) Experience with the Cerebellar Medulloblastoma: Critical Review. Acta pathologica et microbiologica Scandinavica, 7, 1-86. https://doi.org/10.1111/j.1600-0463.1930.tb06503.x

[3] Due-Tonnessen, B.J. and Helseth, E. (2007) Management of Hydrocephalus in Children with Posterior Fossa Tumors: Role of Tumor Surgery. Pediatric Neurosurgery, 43, 92-96. https://doi.org/10.1159/000098379

[4] Foreman, P., McClugage, S. III, Naftel, R., Griessenauer, C.J., Ditty, B.J., Agee, B.S., et al. (2013) Validation and Modification of a Predictive Model of Postresection Hydrocephalus in Pediatric Patients with Posterior Fossa Tumors. Journal of Neurosurgery: Pediatrics, 12, 220-226. https://doi.org/10.3171/2013.5.PEDS1371

[5] Kulkarni, A.V., Piscione, J., Shams, I. and Bouffet, E. (2013) Long Term Quality of Life in Children Treated for Posterior Fossa Brain Tumors. Journal of Neurosurgery: Pediatrics, 12, 235-240. https://doi.org/10.3171/2013.6.PEDS12535

[6] Riva-Cambrin, J., Detsky, A.S., Lamberti-Pasculli, M., Sargent, M.A., Armstrong, D., Moineddin, R., et al. (2009) Predicting Postresection Hydrocephalus in Pediatric Patients with Posterior Fossa Tumors. Journal of Neurosurgery: Pediatrics, 3, 378-385. https://doi.org/10.3171/2009.1.PEDS08298

[7] Gopalakrishnan, C.V., Dhakoji, A., Menon, G. and Nair, S. (2012) Factors Predicting the Need for Cerebrospinal Fluid Diversion Following Posterior Fossa Tumor Surgery in Children. Pediatric Neurosurgery, 48, 93-101. https://doi.org/10.1159/000343009

[8] Abou-Madawi, A. (2007) VP-Shunt Requirement in Patients with Posterior Fossa Tumors. Suez Canal Univ Med J, 10, 121-128.

[9] Santos de Oliveira, R., Barros, J.C.E., Valera, E.T., and Machado, H.R. (2008) Hydrocephalus in Posterior Fossa Tumors in Children. Are there Factors that Determine a Need for Permanent Cerebrospinal Fluid Diversion? Child's Nervous System, 24, 1397-1403. https://doi.org/10.1007/s00381-008-0649-x

[10] Nagy, M.R. and El-Beltagy, M.A. (2012) Cerebrospinal Fluid Diversion Procedures in Children with Posterior Fossa Tumors: Ventriculoperitoneal Shunts versus Endoscopic Third Ventriculostomy versus External Ventricular Drainage. Medical Journal of Cairo University, 80, 249-254.

[11] Schijman, E., Peter, J.C., Rekate, H.L., Sgouros, S. and Wong, T.T. (2004) Management of Hydrocephalus in Posterior Fossa Tumors: How, What, When? Childs 
Nervous System, 20, 192-194. https://doi.org/10.1007/s00381-003-0900-4

[12] Abraham, J. and Chandy, J. (1963) Ventriculo-Atrial Shunt in the Management of Posterior Fossa Tumors. Preliminary Report. Journal of Neurosurgery, 20, 252-253. https://doi.org/10.3171/jns.1963.20.3.0252

[13] Albright, L. and Reigel, D.H. (1977) Management of Hydrocephalus Secondary to Posterior Fossa Tumors. Journal of Neurosurgery, 46, 52-55. https://doi.org/10.3171/jns.1977.46.1.0052

[14] McLaurin, R.L. (1985) On the Use of Precraniotomy Shunting in the Management of Posterior Fossa Tumors in Children: A Cooperative Study. In: Chapman, P.H., Ed., Concepts in Pediatric Neurosurgery, Vol. 6, Karger, New York, 1-5.

[15] Cushing, H. (1931) Experiences with the Cerebellar Astrocytoma. A Clinical Review of Seventy-Six Cases. Surgery, Gynecology \& Obstetrics, 52, 129-204.

[16] Goel, A. (1993) Whether Preoperative Shunts for Posterior Fossa Tumors? British Journal of Neurosurgery, 7, 395-399. https://doi.org/10.3109/02688699309103494

[17] Jiang, C., Wu, X., Lin, Z., Wang, C. and Kang, D. (2013) External Drainage with an Ommaya Reservoir for Perioperative Hydrocephalus in Children with Posterior Fossa Tumors. Child s Nervous System, 29, 1293-1297. https://doi.org/10.1007/s00381-013-2078-8

[18] Islam, M.R., Islam, K.M.T., Hossain, M., Rashid, M.H., Dhakhal, S., Khair, A., et al. (2011) Clinical Outcome of Posterior Fossa Tumor Surgery without Preoperative Ventriculoperitoneal Shunt. Bangladesh Journal of Medicine, 40, 43-47.

[19] Ghani, E., Zaidi, G.I., Nadeem, M., Rehman, L., Noman, M.A. and Khaleeq-Uz-Zaman. (2003) Role of Cerebrospinal Fluid Diversion in Posterior Fossa Tumor Surgery. Journal of the College of Physicians and Surgeons, 13, 333-336.

[20] Sainte-Rose, C., Cinalli, G., Roux, F.E., Maixner, W., Chumas, P.D., Mansour, M., et al. (2001) Management of Hydrocephalus in Pediatric Patients with Posterior Fossa Tumors: The Role of Endoscopic Third Ventriculostomy. Journal of Neurosurgery, 95, 791-797. https://doi.org/10.3171/jns.2001.95.5.0791

[21] Dias, M.S. and Albright, A.L. (1989) Management of Hydrocephalus Complicating Childhood Posterior Fossa Tumors. Pediatric Neurosurgery, 15, 283-290. https://doi.org/10.1159/000120484

[22] Bhatia, R., Tahir, M. and Chandler, C.L. (2009) The Management of Hydrocephalus in Children with Posterior Fossa Tumors: The Role of Pre-Resectional Endoscopic Third Ventriculostomy. Pediatric Neurosurgery, 45, 186-191. https://doi.org/10.1159/000222668

[23] Rappaport, Z.H. and Shalit, M.N. (1989) Perioperative External Ventricular Drainage in Obstructive Hydrocephalus Secondary to Infratentorial Brain Tumors. Acta Neurochirurgic, 96, 118-121. https://doi.org/10.1007/BF01456169

[24] Schmid, U.D. and Seiler, R.W. (1986) Management of Obstructive Hydrocephalus Secondary to Posterior Fossa Tumors by Steroids and Subcutaneous Ventricular Catheter Reservoir. Journal of Neurosurgery, 65, 649-653. https://doi.org/10.3171/jns.1986.65.5.0649

[25] Habib, H.A.M. (2013) Intraoperative Precautionary Insertion of External Ventricular Drainage Catheters in Posterior Fossa Tumors Presenting with Hydrocephalus. Alexandria Journal of Medicine, 50, 333-340. https://doi.org/10.1016/j.ajme.2013.11.001

[26] Korinek, A.M., Reina, M., Boch, A.L., Rivera, A.O., De Bels, D. and Puybasset, L. (2005) Prevention of External Ventricular Drain-Related Ventriculitis. Acta Neurochirurgica, 147, 39-45. https://doi.org/10.1007/s00701-004-0416-Z 
[27] Kulkarni, A.V., Drake, J.M. and Lambert-Pasculli, M. (2001) Cerebrospinal Fluid Shunt Infection: A Prospective Study of Risk Factors. Journal of Neurosurgery, 94, 195-201. https://doi.org/10.3171/jns.2001.94.2.0195

[28] Lo, C.H., Spelman, D., Bailey, M. (2007) External Ventricular Drain Infections Are Independent of Drain Duration: An Argument against Elective Revision. Journal of Neurosurgery, 106, 378-383. https://doi.org/10.3171/jns.2007.106.3.378

[29] Dasic, D., Hanna, S.J., Bojanic S. (2006) External Ventricular Drain Infection: The Effect of a Strict Protocol on Infection Rates and a Review of the Literature. British Journal of Neurosurgery, 20, 296-300. https://doi.org/10.1080/02688690600999901

[30] Tamburrini, G., Massimi, L., Caldarelli, M. and Di Rocco, C. (2008) Antibiotic Impregnated External Ventricular Drainage and Third Ventriculostomy in the Management of Hydrocephalus Associated Posterior Cranial Fossa Tumors. Acta Neurochirurgica, 150, 1049-1055. https://doi.org/10.1007/s00701-008-0022-6

[31] Culley, D.J., Berger, M.S., Shaw, D. (1994) An Analysis of Factors Determining the Need for Ventriculoperitoneal Shunts after Posterior Fossa Tumor Surgery in Children. Neurosurgery, 34, 402-408.

https://doi.org/10.1227/00006123-199403000-00003

[32] Serlo, W., Fernell, E., Heikkinen, E., Anderson, H. and von Wendt, L. (1990) Functions and Complications of Shunts in Different Etiologies of Childhood Hydrocephalus. Child s Nervous System, 6, 92-94. https://doi.org/10.1007/BF00307928

\section{Submit or recommend next manuscript to SCIRP and we will provide best service for you:}

Accepting pre-submission inquiries through Email, Facebook, LinkedIn, Twitter, etc. A wide selection of journals (inclusive of 9 subjects, more than 200 journals) Providing 24-hour high-quality service User-friendly online submission system Fair and swift peer-review system Efficient typesetting and proofreading procedure Display of the result of downloads and visits, as well as the number of cited articles Maximum dissemination of your research work

Submit your manuscript at: http://papersubmission.scirp.org/ Or contact ojped@scirp.org 